\title{
Binding and Covalent Cross-linking of Purified von Willebrand Factor to Native Monomeric Collagen
}

Paula Bockenstedt, Jan McDonagh, and Robert I. Handin

Hemostasis Unit, Hematology Division, Department of Medicine, Brigham and Women's Hospital, Department of Pathology, Beth Israel

Hospital, and Departments of Medicine and Pathology, Harvard Medical School, Boston, Massachusetts 02115

\begin{abstract}
We have analyzed the interaction of the adhesive glycoprotein, von Willebrand factor (vWF), with native monomeric collagen monolayers by adsorbing acid soluble Types I and III collagen derived from calf skin to polystyrene microtiter wells and incubating the wells with purified human ${ }^{125}$ I-vWF. The binding of ${ }^{125}$ I-vWF was saturable, reversible, specific, and was abolished by heat denaturation of the collagen monomers. Binding was half-maximal at $5 \mu \mathrm{g} / \mathrm{ml}$, and, at saturation, $7.5 \mathrm{ng}{ }^{125} \mathrm{I}-\mathrm{vWF}$ were bound to each microgram of immobilized collagen. ${ }^{125} \mathrm{I}$ vWF did not bind to wells coated with other extracellular matrix or plasma proteins such as fibronectin, fibrinogen, gelatin, or the $q$ subunit of the first component of complement (Clq). In addition, bound ${ }^{125} \mathrm{I}-\mathrm{vWF}$ could not be displaced from collagen by the addition of either fibronectin or fibrinogen. After incubation with Factor XIIIa, plasma transglutaminase, ${ }^{125} \mathrm{I}-\mathrm{vWF}$ bound to collagen could no longer be displaced by $\mathrm{VWF}$, which suggests covalent cross-linking of $\mathbf{v W F}$ to collagen monomers. Factor XIIIa-dependent covalent cross-linking of vWF to collagen, but not to fibronectin or laminin, was also demonstrated by polyacrylamide gel electrophoresis in the presence of sodium dodecyl sulfate.
\end{abstract}

\section{Introduction}

von Willebrand Factor (vWF) $)^{1}$ plays an important role in the initial adhesion of platelets to vascular subendothelium $(1,2)$. Because of the polymeric nature of the vWF protein, its relatively low plasma concentration, and the complexity of the subendothelial matrix, the nature of vWF binding to subendothelial matrix components has not yet been fully defined. Previous studies of the interaction of vWF, platelets, and denuded subendothelium have utilized everted vessel segments $(1,3,4)$, matrix produced by cultured endothelial cells $(5,6)$, and monoclonal antibodies to selected vWF epitopes $(1,4)$. These studies have clearly demonstrated that vWF binds to subendothelium. In addition, selective protease digestion has implicated collagen as one potential binding site for plasma vWF (4-6). Several inves-

Address reprint requests to Dr. Handin, Hematology Division, Brigham and Women's Hospital, 75 Francis St., Boston, MA 02115. 1986.

Received for publication 16 April 1985 and in revised form 23 April

1. Abbreviations used in this paper: $\mathrm{Clq}$, the $\mathrm{q}$ subunit of the first component of complement; PAGE, polyacrylamide gel electrophoresis; PEG, polyethylene glycol; TBS, $10-15 \mathrm{ml}$ of $0.05 \mathrm{M}$ Tris, $0.15 \mathrm{M} \mathrm{NaCl}, 0.02 \%$ sodium azide, $\mathrm{pH} 7.4$; vWF, von Willebrand Factor.

J. Clin. Invest.

(C) The American Society for Clinical Investigation, Inc. 0021-9738/86/08/0551/06 \$1.00

Volume 78, August 1986, 551-556 tigators have reported the binding of vWF to suspensions of microfibrillar collagen (7-11), while others have suggested that vWF binds to noncollagenous microfibrils extracted from bovine aortae (12) or to noncollagenous constituents in the matrix derived from cultured endothelial cells (13).

While some of these reports clearly demonstrate an interaction between vWF and collagen, the biochemical nature of the interaction is not understood. The form of collagen used in some binding assays may differ from the collagen present in vascular subendothelium. In vivo, collagen is present as a surface network of discrete bundles interwoven with other extracellular matrix constituents, including fibronectin, laminin, and certain species of glycosaminoglycans (14-17). There may also be a role for additional adhesive glycoproteins like fibronectin, fibrinogen, and thrombospondin in vWF-collagen or vWF-platelet interactions. Finally, there are no studies that compare the binding characteristics of the platelet granule, plasma, and subendothelial pools of VWF, nor is there any information on possible mechanisms to stabilize the interaction of vWF with matrix proteins like collagen or laminin.

Fibrin (18), fibronectin (19), and $\alpha_{2}$ antiplasmin (20) are three substrates for Factor XIIIa. There is a specific cross-linking domain on fibronectin, separate from the collagen-binding domain, that is cross-linked to collagen $(21,22)$. As a first step toward understanding the complex interactions that regulate vWF binding to subendothelium, we have developed methods to quantitate vWF binding to purified monomeric collagen and have defined a highly specific reversible interaction with collagen. In addition, we have demonstrated the formation of irreversible vWF-collagen cross-links catalyzed by Factor XIIIa.

\section{Methods}

Immulon I microtiter wells were obtained from Dynatech Laboratories, Inc., Alexandria, VA. The following reagents were used: Iodobeads (Pierce Chemical Co., Rockford, IL); ${ }^{125}$ I-Na (New England Nuclear, Boston, MA); Sephacryl S 1000 and Sepharose CL6B (Pharmacia Fine Chemicals, Piscataway, NJ); Affi-gel Gelatin Sepharose, high molecular weight standards, and sodium dodecyl sulfate (SDS) (Bio-Rad Laboratories, Richmond, CA); acid-soluble calfskin collagen (Worthington Diagnostics Div., Millipore Corp., Freehold, NJ); mouse laminin (Bethesda Research Laboratories, Gaithersburg, MD); ristocetin (Bio/Data Corp., Horsham, PA); bovine thrombin (Miles Laboratories, Elkhart, IN); type III gelatin, bovine serum albumin (BSA), gamma globulin, fibrinogen, polyethylene glycol relative molecular weight $\left(M_{\mathrm{r}}\right) 8,000$ and $M_{\mathrm{r}} 20,000$, dithiothreitol (DTT), EDTA, and beta-mercaptoethanol (Sigma Chemical Co., St. Louis, MO). Purified Clq was obtained from CalBiochem-Behring Corp., La Jolla, CA. Purified human fibronectin and purified Factor XIII were prepared as previously described $(23,24)$. Identical results were obtained with highly purified Factor XIII and with a product of intermediate purity (containing albumin). Hence, the intermediate product was used for many experiments. All other chemicals were reagent grade or better.

$v W F$ purification. $v W F$ was purified by a modification of the procedure of Kao et al. (25). 5 liters of plasma, obtained within 2-3 d of collection from the American Red Cross Blood Services-Northeast Re- 
gion (Boston, MA), frozen at $-20^{\circ} \mathrm{C}$ for $24 \mathrm{~h}$, and thawed at $4^{\circ} \mathrm{C}$ for 18 $\mathrm{h}$, was used as the starting material rather than partially purified commercial VIII concentrates. The resulting cryoprecipitate was collected by centrifugation at $6,500 \mathrm{~g}$ for $20 \mathrm{~min}$, resuspended in $20 \mathrm{mM} \mathrm{Na}$ citrate, $\mathrm{pH}$ 6.1, and reprecipitated twice with final concentrations of 5 and $12 \%$ polyethylene glycol (PEG) as previously described (25). The final precipitate was collected by centrifugation at $6,500 \mathrm{~g}$ for $20 \mathrm{~min}$, the pellet surface was washed twice with ice cold $0.02 \mathrm{M}$ Tris $0.15 \mathrm{M}$ $\mathrm{NaCl}, 8 \%$ ethanol, pH 7.4 to remove residual PEG, and resuspended in $10-15 \mathrm{ml}$ of $0.05 \mathrm{M}$ Tris, $0.15 \mathrm{M} \mathrm{NaCl}, 0.02 \%$ sodium azide, $\mathrm{pH} 7.4$ (TBS) and applied to a $2.5 \times 90 \mathrm{~cm}$ siliconized glass column containing Sephacryl S 1000. 4-ml fractions, collected at a $70 \mathrm{ml}$ per hour flow rate, were analyzed for ristocetin-dependent platelet-agglutinating activity, protein concentration by the method of Lowry (26), and for purity by 5\% SDS-polyacrylamide gel electrophoresis (PAGE) (27) after disulfide bond reduction, as described below. Those fractions exhibiting both maximal ristocetin cofactor activity per milligram protein and demonstrating a single 220,000-molecular-weight band on 5\% SDS-PAGE were pooled and concentrated by dialysis against $20 \% \operatorname{PEG}\left(M_{\mathrm{r}}, 20,000\right)$. Purified vWF was stored frozen at $-20^{\circ} \mathrm{C}$ in $250-\mu \mathrm{l}$ aliquots for up to 3 wk.

Iodination of $v W F$ and collagen. To remove any contaminating fibronectin (27), $300 \mu \mathrm{g}$ of purified $\mathrm{vWF}$ were chromatographed on a 1$\mathrm{ml}$ column of gelatin Sepharose preequilibrated with TBS. Fractions of the flow through volume containing ristocetin cofactor activity were pooled before iodination. $500 \mu \mathrm{g}$ of acid-soluble calf skin collagen were dialyzed extensively against distilled water at $4^{\circ} \mathrm{C}$. The dialysate was divided into $100-\mu \mathrm{g}$ aliquots, frozen rapidly in a dry ice-acetone bath, lyophilized, and stored at $-20^{\circ} \mathrm{C}$ until further use. Immediately before iodination, the lyophilized collagen was resuspended in $1 \mathrm{ml}$ TBS and left on ice. Both proteins were labeled with the iodobead technique. In each case, one iodobead was preincubated for $10 \mathrm{~min}$ with $0.5-1 \mathrm{mCi}$ ${ }^{125} \mathrm{I}-\mathrm{Na}$, followed by addition of $100 \mu \mathrm{g} v \mathrm{vW}$. After $10 \mathrm{~min}$ at room temperature, iodination was stopped by transfer of the vWF solution to a $0.7 \times 10 \mathrm{~cm}$ Sephadex G-25 column preequilibrated with $1 \mathrm{mg} / \mathrm{ml}$ BSA in TBS and eluted with TBS. Typical specific radioactivity of vWF was $0.20-0.23 \mu \mathrm{Ci} / \mu \mathrm{g}$ protein. vWF retained $90 \%$ of its initial platelet agglutinating activity after iodination. ${ }^{125} \mathrm{I}-\mathrm{vWF}$ also co-migrated with unlabeled vWF as a single band $\left(M_{\mathrm{r}}, 220,000\right)$ on 5\% SDS-PAGE after disulfide reduction. Radiolabeled $\mathrm{vWF}$ was used within $3 \mathrm{~d}$ of iodination.

After $15 \mathrm{~min}$, the radiolabeled collagen solution was dialyzed exhaustively for $48 \mathrm{~h}$ against $0.05 \mathrm{M}$ acetic acid. Radiolabeled collagen typically had a specific activity of $0.17-0.20 \mu \mathrm{Ci} / \mu \mathrm{g}$ and, at a concentration of $8 \mu \mathrm{g} / \mathrm{ml}$, was capable of inducing aggregation of platelet-rich plasma equivalent to that of a $10 \mu \mathrm{g} / \mathrm{ml}$ solution of unlabeled collagen. $5 \%$ SDSPAGE (27) of reduced radiolabeled collagen showed four major bands with molecular weights consistent with the $\alpha_{1}, \alpha_{2}$, and $\beta$-chains of calf skin collagen and trace $(<1 \%)$ contamination with fibronectin.

Collagen-coated plates. An extract of calf skin containing $~ 60 \%$ type I and $40 \%$ type III collagen was diluted in $0.05 \mathrm{M}$ acetic acid to $1.87 \mathrm{mg} / \mathrm{ml} .100-\mu \mathrm{l}$ aliquots of this collagen solution were added to individual flat-bottomed microtiter wells and incubated for $1.5 \mathrm{~h}$ at room temperature. The solution was then removed by gentle aspiration, and the wells were washed once with $1 \mathrm{mg} / \mathrm{ml} \mathrm{BSA}$ in TBS, decanted, and then refilled completely with the albumin solution. After $1 \mathrm{~h}$ incubation at room temperature, the albumin solution was completely removed by gentle suction, and the plates were immediately used for VWF binding assays. In some experiments, acid-soluble collagen was denatured by heating in $0.05 \mathrm{M}$ acetic acid for $1 \mathrm{~h}$ at $60^{\circ} \mathrm{C}$. Wells containing other extracellular matrix constituents were prepared in a fashion similar to that described for collagen. All stock solutions of fibronectin, fibrinogen, albumin, gamma globulin, and Clq were diluted to $2.5 \mathrm{mg} / \mathrm{ml}$ in TBS.

Quantitation of collagen bound to wells. Sufficient ${ }^{125} \mathrm{I}$-collagen was added to $1.87 \mathrm{mg} / \mathrm{ml}$ of nonradioactive collagen to give a final specific radioactivity of $0.45 \mu \mathrm{Ci} / \mathrm{mg}$, and serial dilutions were made from this stock solution. Concentrations of ${ }^{125} \mathrm{I}$-collagen from $0.47 \mathrm{mg} / \mathrm{ml}$ to 1.87 $\mathrm{mg} / \mathrm{ml}$ were then incubated in flat-bottomed microtiter wells as previously described for 0.5 to $3 \mathrm{~h}$ at 4 and $25^{\circ} \mathrm{C}$ to optimize binding conditions.
At the highest concentration, $10 \mu \mathrm{g}$ collagen bound to each well. All incubations were terminated by aspiration of unbound radiolabeled collagen, and plates were washed and coated with albumin solutions as described above. Individual microtiter wells were detached, and total bound radiolabeled collagen was determined in a Gamma 8000 Spectrometer (Beckman Instruments, Inc., Fullerton, CA). Unless otherwise specified, all collagen-coated plates were typically prepared using a stock collagen solution of $1.87 \mathrm{mg} / \mathrm{ml}$ and a $90-\mathrm{min}$ incubation period at room temperature. Binding of gelatin to microtiter plates was assessed by using heat-denatured radiolabeled collagen.

$v W F$ binding assay. Varying concentrations of ${ }^{125} \mathrm{I}-\mathrm{vWF}$ were added to collagen-coated wells in the presence or absence of a 20-fold excess of nonradiolabeled vWF. Additional TBS was added to make the final volume $100 \mu \mathrm{l}$, and samples were incubated for $1 \mathrm{~h}$ at room temperature. The incubation was terminated by gentle aspiration of unbound vWF, and wells were washed three times with TBS. Bound radiolabeled vWF was determined by counting individual wells as described above. Specifically bound vWF was defined as total bound radioactivity minus radioactivity bound in wells containing a 20 -fold excess of nonlabeled vWF.

Factor XIII a cross-linking of $v W F$ in collagen-coated wells. In some experiments, intermediate purity Factor XIII containing $0.5 \mathrm{mg} / \mathrm{ml} \mathrm{al-}$ bumin was activated with $5 \mathrm{U} / \mathrm{ml}$ bovine thrombin in the presence of $10 \mathrm{mM}$ calcium and $4 \mathrm{mM}$ dithiothreitol for $20 \mathrm{~min}$ at $37^{\circ} \mathrm{C}$. Thrombin was inactivated by addition of the irreversible inhibitor $\mathrm{D}$-phenylalanylL-prolyl-L-arginine chloromethyl ketone (PPACK) (28) before use of the activated Factor XIII (XIIIa) in assays. $1 \mu \mathrm{g} / \mathrm{ml}^{125} \mathrm{I}$-vWF was incubated with Factor XIIIa in the presence or absence of EDTA in parallel collagencoated wells for $60 \mathrm{~min}$ at room temperature. After dilution, the final concentration of DTT varied from 0.4 to $0.6 \mathrm{mM}$. Incubation of vWF with this concentration of DTT did not change vWF multimer distribution when analyzed by SDS-agarose gel electrophoresis. The wells were then aspirated, washed twice with TBS containing $15 \mathrm{mM}$ EDTA, and bound radioactivity was measured. To determine whether the ${ }^{125} \mathrm{I}-\mathrm{vWF}$ was covalently bound to the collagen-coated wells, a 100 -fold excess of nonlabeled vWF in TBS 5 mM EDTA, pH 7.4, or TBS 5 mM EDTA, pH 7.4 alone was added to the remaining duplicate wells. The wells were incubated for an additional $45 \mathrm{~min}$ to permit the added vWF to displace any noncovalently bound ${ }^{125} \mathrm{I}-\mathrm{vWF}$. Wells were then aspirated and washed three times with $5 \mathrm{mM}$ EDTA and bound radioactivity was measured.

Factor XIII a cross-linking of $v W F$ to other proteins. Factor XIII was activated as above. $10 \mu \mathrm{g} / \mathrm{ml}{ }^{125} \mathrm{I}-\mathrm{vWF}$ were incubated with either buffer, $100 \mu \mathrm{g} / \mathrm{ml}$ calf-skin collagen in TBS, $100 \mu \mathrm{g} / \mathrm{ml}$ laminin in TBS, pH 7.8 , or $200 \mu \mathrm{g} / \mathrm{ml}$ human fibronectin in TBS, in the presence of $1 \mathrm{mM}$ DTT, $2.5 \mathrm{U} / \mathrm{ml}$ Factor XIIIa, and either $10 \mathrm{mM}$ calcium or $5 \mathrm{mM}$ EDTA. A unit of Factor XIIIa is the amount of enzyme contained in $1 \mathrm{ml}$ of normal human plasma. Incubations were carried out at room temperature for up to $6 \mathrm{~h}$ with individual test tubes for each time point. At the indicated time, $25 \mu$ l of Laemmli sample buffer containing a final concentration of $6 \mathrm{M}$ urea were added, and the sample was boiled at $100^{\circ} \mathrm{C}$ for $5 \mathrm{~min}$ before 4.3\% SDS-PAGE. The gels were then fixed, stained with Coomassie Brilliant Blue, dried, and autoradiograms were prepared.

Ristocetin cofactor activity. Formalin-fixed platelets were prepared as previously described and suspended at a final concentration of $4 \times 10^{5}$ platelets/ $\mu$ lin TBS (29). The ability of native vWF polymers to agglutinate formalin-fixed platelets was determined in the presence of $1 \mathrm{mg} / \mathrm{ml}$ ristocetin $(30,31)$, and agglutination was monitored on a dual-channel aggregometer (Payton Assoc., Inc., Buffalo, NY).

\section{Results}

As shown in Fig. 1, ${ }^{125} \mathrm{I}$-vWF bound to immobilized types I and III collagen monomers derived from calf skin in a specific and saturable manner, with half-maximal binding at $5 \mu \mathrm{g} / \mathrm{ml}$ at room temperature and $\mathrm{pH}$ 7.4. At saturation, $7.5 \mathrm{ng}$ of multimeric vWF was specifically bound to each microgram of immobilized collagen. At the highest concentration of added ${ }^{125} \mathrm{I}-\mathrm{vWF}$, non- 


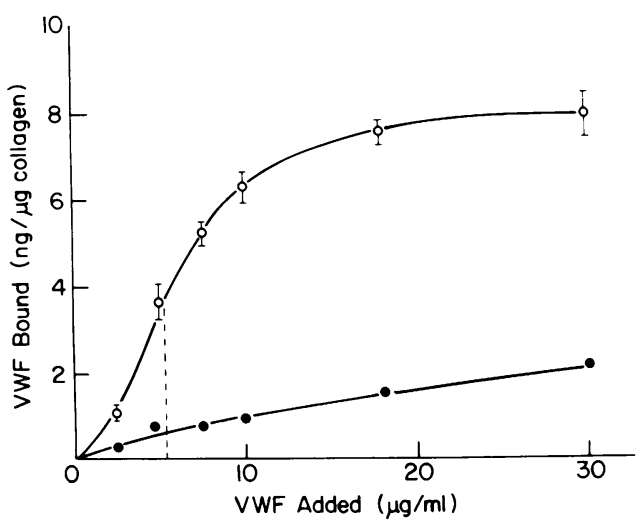

Figure 1. Binding of ${ }^{125} \mathrm{I}-\mathrm{vWF}$ to collagen-coated Immulon I microtiter wells. Individual wells were incubated with $1.87 \mathrm{mg} / \mathrm{ml}$ collagen in $0.05 \mathrm{M}$ acetic acid, the collagen solution was aspirated, and the wells were washed once with $0.05 \mathrm{M}$ Tris, $0.15 \mathrm{M} \mathrm{NaCl}, \mathrm{pH} 7.4$ (TBS), containing $1 \mathrm{mg} / \mathrm{ml}$ albumin. Incubations were performed in these wells for $1 \mathrm{~h}$ at $24^{\circ} \mathrm{C}$ by adding increasing concentrations of ${ }^{125} \mathrm{I}-\mathrm{vWF}$. Incubations were terminated by aspiration of the radioactive vWF solution followed by washing three times with TBS. Open circles represent specific binding of $\mathrm{vWF}$ and closed circles represent nonspecific binding, determined by adding nonradioactive vWF equal to 20 times the highest concentration of ${ }^{125} \mathrm{I}-\mathrm{vWF}$. Mean \pm SEM for six separate experiments done in duplicate is depicted. The dotted line marks the concentration of ${ }^{125} \mathrm{I}-\mathrm{vWF}$ required to saturate $50 \%$ of collagen binding sites.

specific binding accounted for $10-20 \%$ of the total bound radioactivity. The binding of ${ }^{125} \mathrm{I}-\mathrm{vWF}$ to collagen increased with length of incubation (Fig. 2), reaching equilibrium at $1 \mathrm{~h}$. The binding of ${ }^{125} \mathrm{I}-\mathrm{vWF}$ was reversed by the addition of a 100 -fold excess of unlabeled vWF. $45 \%$ of the bound radiolabeled vWF was rapidly dissociated from collagen within $10 \mathrm{~min}$ of adding a 100-fold excess of vWF to incubations in which the binding of ${ }^{125} \mathrm{I}-\mathrm{vWF}$ reached equilibrium (Fig. 2). Further dissociation of bound vWF from collagen occurred more slowly, with $\sim 15 \%$ of bound vWF remaining at $2 \mathrm{~h}$. In wells in which only buffer

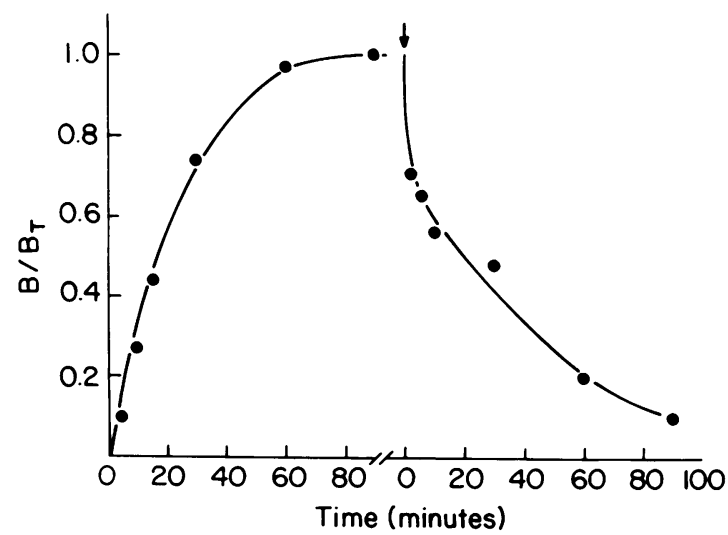

Figure 2. Time course of ${ }^{125} \mathrm{I}-\mathrm{vWF}$ binding to collagen-coated wells. Collagen-coated wells were incubated with $10 \mu \mathrm{g} / \mathrm{ml}$ of ${ }^{125} \mathrm{I}-\mathrm{vWF}$ for varying periods of time as in Fig. 1. At the arrow, a 100-fold excess of nonradioactive $\mathrm{vWF}$ was added to the remaining wells and the dissociation of bound ${ }^{125} \mathrm{I}-\mathrm{vWF}$ from collagen determined. $\mathrm{B} / \mathrm{B}_{\mathrm{T}}$ is the fraction of added ${ }^{125} \mathrm{I}-\mathrm{vWF}$ bound (B) divided by the amount bound at equilibrium $\left(B_{T}\right)$. was added, there was no loss of bound ${ }^{125} \mathrm{I}-\mathrm{vWF}$ over the 2 -h test period. Binding was not affected by the addition of up to $15 \mathrm{mM} \mathrm{CaCl}_{2}$.

Specificity of $v W F$ for collagen. Because of the adhesive properties of vWF and the possibility of nonspecific binding, we examined the binding of $\mathrm{vWF}$ to wells coated with other proteins. $10 \mu \mathrm{g} / \mathrm{ml}$ of ${ }^{125} \mathrm{I}-\mathrm{vWF}$, a concentration which saturates binding sites on collagen-coated wells, did not bind to wells coated with albumin, human fibronectin, bovine fibrinogen, gamma globulin, commercial grade calf skin gelatin, or to wells coated with thermally denatured monomeric calf skin collagen prepared by heating collagen at $60^{\circ} \mathrm{C}$ for $1 \mathrm{~h}$ (Fig. 3). The lack of binding of radiolabeled vWF to denatured collagen was not due to a decreased binding of denatured collagen to microtiter wells since studies using radiolabeled collagen indicated the binding to be similar (10 $\mu \mathrm{g} /$ well for native collagen vs. $8 \mu \mathrm{g} /$ well for denatured collagen). In addition, there was no demonstrable binding to wells coated with Clq, a component of human complement with amino acid sequences and tertiary structural similarities to collagen (32).

Since there is an 80 -fold higher concentration of fibronectin and fibrinogen in plasma when compared to $\mathrm{VWF}$, we examined their effects on vWF binding to collagen. Fig. 4 shows that neither fibronectin nor fibrinogen, in concentrations ranging from 2.4 to $240 \mu \mathrm{g} / \mathrm{ml}$, competed for the binding of $4 \mu \mathrm{g} / \mathrm{ml}{ }^{125} \mathrm{I}-\mathrm{vWF}$ to collagen. The $\mathrm{IC}_{50}$ for $\mathrm{vWF}$ in these competition experiments was $8-11 \mu \mathrm{g} / \mathrm{ml}$, consistent with the half-maximal binding at 5 $\mu \mathrm{g} / \mathrm{ml}$ estimated in Fig. 1 from the direct binding of ${ }^{125} \mathrm{I}-\mathrm{vWF}$ to collagen.

We then studied the effects of incubating vWF and collagen in the presence of Factor XIIIa (Table I). After the addition of Factor XIIIa, but in the presence of the calcium chelator EDTA, $100 \mu \mathrm{g} / \mathrm{ml}$ nonradioactive vWF displaced $90 \%$ of the bound ${ }^{125} \mathrm{I}-$ $\mathrm{vWF}$, the same as in controls without Factor XIIIa. In contrast, in those wells incubated in the presence of Factor XIIIa without

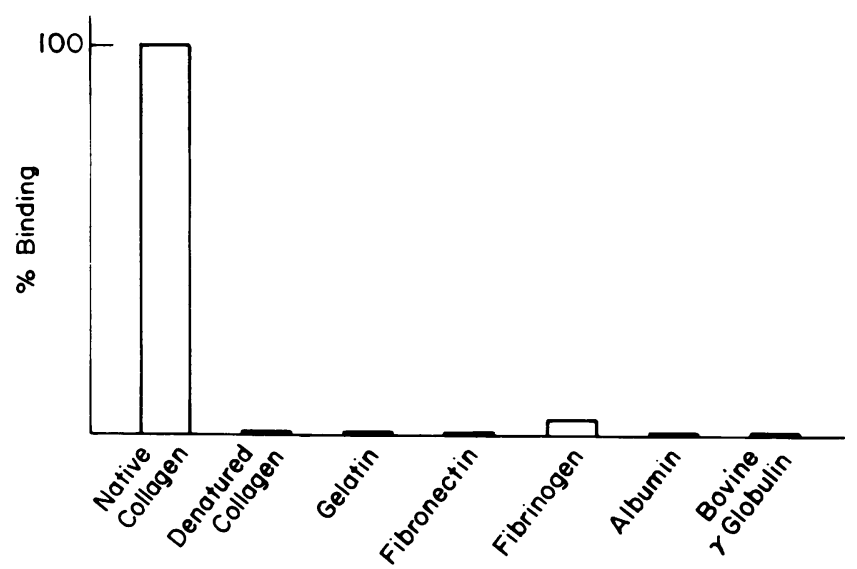

Figure 3. Binding of ${ }^{125} \mathrm{I}-\mathrm{vWF}$ to wells coated with various plasma or matrix proteins. $10 \mu \mathrm{g} / \mathrm{ml}$ of ${ }^{125} \mathrm{I}-\mathrm{vWF}$ was incubated for $60 \mathrm{~min}$ in wells that had been previously coated with $1.87 \mathrm{mg} / \mathrm{ml}$ calf skin collagen in $0.05 \mathrm{M}$ acetic acid (native collagen), an identical solution that had been heated to $60^{\circ} \mathrm{C}$ for $1 \mathrm{~h}$ (denatured collagen), or equal concentrations of fibronectin, bovine fibrinogen, gamma globulin, and commercial grade calf skin gelatin and albumin. Specific binding of ${ }^{125} \mathrm{I}-\mathrm{vWF}$, defined as the fraction of ${ }^{125} \mathrm{I}$-vWF displaced by a 20 -fold excess of nonradioactive VWF, is graphed with the specific binding obtained in the wells coated with native collagen defined as $100 \%$. 


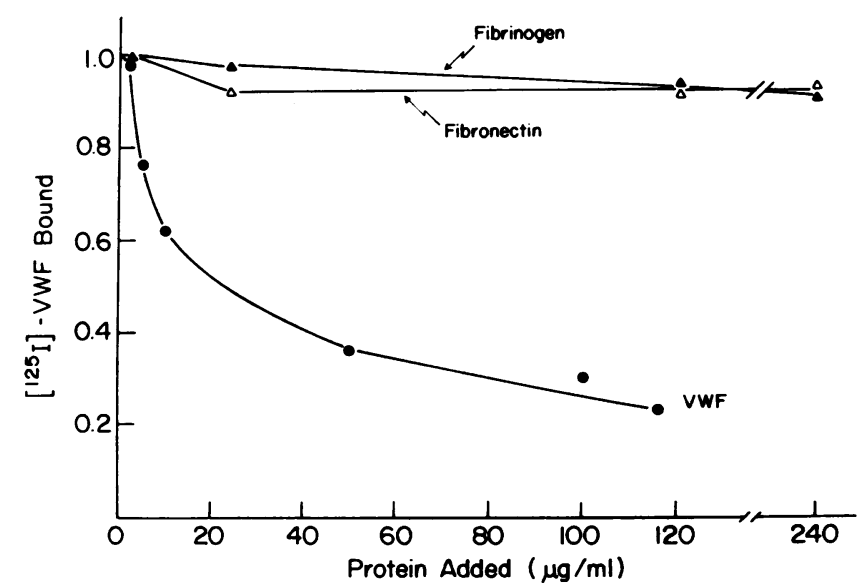

Figure 4. Displacement of ${ }^{125} \mathrm{I}-\mathrm{vWF}$ from collagen-coated wells by fibronectin, fibrinogen, and vWF. Incubations were performed using 4 $\mu \mathrm{g} / \mathrm{ml}{ }^{125} \mathrm{I}-\mathrm{vWF}$ and up to $240 \mu \mathrm{g} / \mathrm{ml}$ fibronectin, fibrinogen, or vWF for $60 \mathrm{~min}$ at $24^{\circ} \mathrm{C}$. The fraction bound (B) divided by the amount bound without any added fibronectin, fibrinogen, or vWF $\left(B_{0}\right)$ is depicted.

the inhibitor EDTA, only $47 \%$ of bound ${ }^{125} \mathrm{I}-\mathrm{vWF}$ was displaced by the same concentration of nonlabeled vWF. In addition, the total amount of vWF bound to wells in the presence of activated Factor XIIIa was 2.7 times that bound in wells incubated in the presence of Factor XIIIa and EDTA or in controls. This was not due to an effect of EDTA on the binding of vWF to collagen, since incubations containing $15 \mathrm{mM}$ EDTA, in the absence of Factor XIIIa, were similar to that seen in control wells containing no Factor XIIIa or EDTA (Table I).

Fig. 5 shows the results of incubating ${ }^{125} \mathrm{I}-\mathrm{vWF}$ and Factor XIII with three subendothelial proteins. Lanes 2-6 show a progressive, time-dependent loss of the 220,000 $M_{\mathrm{r}} \mathrm{vWF}$ subunit and the appearance of higher molecular weight species only in the presence of $2.5 \mathrm{U} / \mathrm{ml}$ Factor XIIIa. These cross-linked species are reflected in the radioactive bands that do not enter the gel or remain at the interface between the stacking and running gel. This change in electrophoretic mobility is most consistent with Factor XIIIa-dependent cross-linking of vWF to collagen. Ad-

Table I. Cross-linking of vWF to Collagen

\begin{tabular}{|c|c|c|}
\hline & ${ }^{125} \mathrm{I}-\mathrm{vWF} / \mathrm{well}^{*}$ & $\begin{array}{l}{ }^{125} \mathrm{I} \text {-vWF/well } \\
\text { after addition of } \\
100 \mu \mathrm{g} / \mathrm{ml} \mathrm{vWF} \neq\end{array}$ \\
\hline & $n g$ & $n g$ \\
\hline${ }^{125} \mathrm{I}-\mathrm{vWF}$ & $24 \pm 2$ & $2.5 \pm 0.5$ \\
\hline${ }^{125} \mathrm{I}-\mathrm{vWF}+15 \mathrm{mM}$ EDTA & $24 \pm 2.7$ & $3.0 \pm 0.4$ \\
\hline${ }^{125} \mathrm{I}-\mathrm{vWF}+15 \mathrm{mM}$ EDTA & & \\
\hline 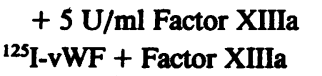 & $22 \pm 2.2$ & $3.0 \pm 0.5$ \\
\hline$+5 \mathrm{mM} \mathrm{CaCl}_{2}$ & $64 \pm 7.1$ & $34.3 \pm 2.2$ \\
\hline
\end{tabular}

* $1 \mu \mathrm{g} / \mathrm{ml}{ }^{125} \mathrm{I}-\mathrm{vWF}$ was incubated with collagen-coated wells in the presence and absence of EDTA and Factor XIIIa for $1 \mathrm{~h}$ at room temperature.

¥ Noncovalently bound ${ }^{125}$ I-vWF was displaced by the addition of 100 $\mu \mathrm{g} / \mathrm{ml}$ nonlabeled $v W F$ and the wells were washed twice with TBS.

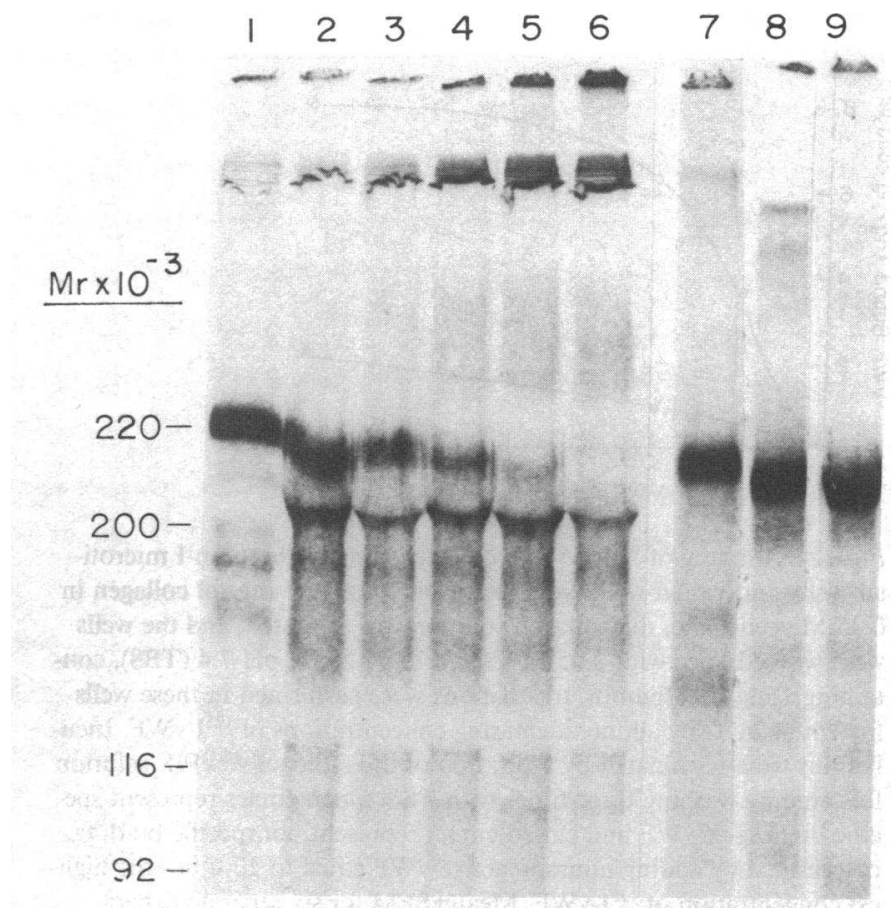

Figure 5. Autoradiographic analysis of Factor XIIIa-dependent crosslinking of $\mathrm{VWF}$ to selected subendothelial proteins on 4.3\% SDSPAGE. $10 \mu \mathrm{g} / \mathrm{ml}{ }^{125} \mathrm{I}-\mathrm{vWF}, 2.5 \mathrm{U} / \mathrm{ml}$ Factor XIIIa, 0.4-0.6 mM DTT, and $10 \mathrm{mM}$ calcium were incubated with buffer, $100 \mu \mathrm{g} / \mathrm{ml}$ calfskin collagen, $100 \mu \mathrm{g} / \mathrm{ml}$ laminin, or $200 \mu \mathrm{g} / \mathrm{ml}$ fibronectin for up to $6 \mathrm{~h}$ at room temperature as described in Methods. Lane 1, collagen, ${ }^{125} \mathrm{I}$ vWF, 5 mM EDTA, Factor XIIla $6 \mathrm{~h}$ incubation; lanes 2-6, collagen, ${ }^{125} \mathrm{I}$-vWF, Factor XIIIa incubated for $0.5,1,2,4$, and $6 \mathrm{~h}$, respectively; lane 7, Factor XIIIa and ${ }^{125} \mathrm{I}$-vWF $6 \mathrm{~h}$ incubation; lane 8, fibronectin, ${ }^{125} \mathrm{I}-\mathrm{vWF}$, and Factor XIIIa, $6 \mathrm{~h}$ incubation; lane 9, laminin, ${ }^{125} \mathrm{I}-\mathrm{vWF}$, and Factor XIIIa $6 \mathrm{~h}$ incubation. Lanes 7, 8, and 9 were selected from three separate gels, accounting for the variation in the size of the stacking gel and mobility of the 220,000 -mol-wt band. Standards: purified vWF, 220,000; myosin heavy chain, 200,000; $\beta$-galactosidase, 116,000; phosphorylase B, 92,000 . The dried gel was exposed to $x$-ray film for $48 \mathrm{~h}$.

dition of $5 \mathrm{mM}$ EDTA inhibits cross-linking of vWF to collagen (lane 1). In the absence of collagen, only trace quantities of vWF were cross-linked into higher molecular weight forms. The band appearing at 200,000-mol-wt may represent the cross-linking of partially degraded vWF polymer which yields low $M_{\mathrm{r}}$ polypeptide subunits.

To examine the specificity of cross-linking of vWF to collagen, we examined the ability of Factor XIIIa to cross-link vWF to laminin and fibronectin, two other subendothelial proteins that do not interact with vWF. As shown in Fig. 5, lanes 8 and 9, vWF cannot be cross-linked to laminin or fibronectin. These results strongly suggest that $\mathrm{vWF}$ is covalently bound to collagen in the presence of activated Factor XIII and calcium.

\section{Discussion}

In these studies, we have shown the highly selective nature of vWF binding and its covalent cross-linking to collagen. Previous investigators have assessed vWF binding to collagen by measuring the depletion of plasma vWF by microfibrillar collagen (7-11). In these studies, binding required fibrillar collagen, im- 
plying a need for a specific quaternary structure. However, vWF can also bind to segment long spacing (SLS) forms of collagen and to type $\mathrm{V}$ collagen $(10,33)$, which are not fibrillar. This suggests that the apparent requirement for collagen fibrils might be related to an inability to separate bound from free vWF by centrifugal techniques. There is also evidence that both the collagen subtype and the molecular form of the collagen influence vWF binding and that vWF may preferentially bind to fibrillar collagen $(33,34)$.

We have now shown that vWF binds saturably and reversibly to immobilized monomeric types I and III collagen with halfmaximal binding at $5 \mu \mathrm{g} / \mathrm{ml}$, a concentration that approximates the plasma concentration of $\mathrm{vWF}(10 \mu \mathrm{g} / \mathrm{ml})$. At saturation, 75 $\mathrm{ng}$ of vWF were bound to the $10 \mu \mathrm{g}$ of collagen monomer adsorbed to each microtiter well. This stoichiometry between vWF and collagen is similar to that reported by Santoro $(7,9)$, who used fibrillar collagen, and found that $600 \mu \mathrm{g}$ of microfibrillar collagen could deplete vWF antigen and activity from $0.5 \mathrm{ml}$ of plasma. Assuming an average plasma vWF concentration of 10 $\mu \mathrm{g} / \mathrm{ml}$, this would represent binding of a total of $5 \mu \mathrm{g} \mathrm{vWF}$ protein or $8 \mathrm{ng}$ vWF per microgram collagen. Morton et al. (10) recently showed that $50 \mu \mathrm{g}$ fibrillar collagen could adsorb $80 \mathrm{ng}$ vWF, a similar binding ratio. In addition, they showed that monomeric collagen could inhibit or compete for binding of ${ }^{125} \mathrm{I}-\mathrm{vWF}$ to fibrillar collagen, although a large excess of monomeric collagen was required. Interpretation of these studies is not unambiguous, since one might anticipate that a $3-4 \mathrm{mg} / \mathrm{ml}$ solution of nondenatured monomeric collagen might form fibrils during a 60 min incubation period.

Binding of vWF to collagen is of sufficiently high affinity that it could occur at the concentrations of vWF present in plasma. Half-maximal binding occurred at $5 \mu \mathrm{g} / \mathrm{ml}$. This amount is equivalent to the lower limit of normal for plasma vWF and suggests that a modest decrease in plasma vWF concentration, similar to that seen in mild von Willebrand's disease, could markedly decrease vWF binding to collagen. This would help explain the occurrence of bleeding observed at plasma vWF concentrations that are $50 \%$ of normal in these patients.

The role of Factor XIIIa in stabilizing the binding of vWF to a subendothelial component has not previously been described. Several other plasma proteins, such as fibronectin (19) and $\alpha_{2}$ antiplasmin (20), have been shown to be substrates for Factor XIIIa. Several studies on the Factor XIIIa-dependent cross-linking of fibronectin to fibrin (35) and collagen (19) have been published. In this report, two lines of evidence are presented which indicate that a fraction of the vWF bound to collagen is also covalently cross-linked to the collagen substrate by Factor XIIIa. The total quantity of ${ }^{125} \mathrm{I}-\mathrm{vWF}$ bound to collagen increases after incubation with Factor XIIIa. Part of the bound ${ }^{125} \mathrm{I}-\mathrm{vWF}$ is covalently cross-linked to collagen by Factor XIIIa, since it is not displaced from the collagen-coated wells by a large molar excess of nonradiolabeled vWF. The fraction that is still displaced by vWF may arise from covalent cross-links between individual vWF molecules which then bind reversibly to collagen.

Factor XIIIa-catalyzed cross-linking is highly specific. In proteins that are Factor XIIIa substrates, only a few specific glutamines and lysines (usually 1-3) can participate in the crosslinking reaction. We have shown here that $\mathrm{VWF}$ can be covalently cross-linked to collagen monomers insolubilized on microtiter wells or to fibrillar collagen suspensions. In contrast, vWF could not be cross-linked to itself or to two other matrix proteins, laminin or fibronectin, despite $6 \mathrm{~h}$ of incubation with Factor
XIIIa. This binding and cross-linking of vWF to collagen appear to be highly specific since we could not demonstrate interaction of vWF with any of the other subendothelial or plasma proteins we tested.

It is of interest to compare the binding characteristics of vWF to fibronectin, another adhesive glycoprotein which binds cells to extracellular matrix. Both proteins are cross-linked to collagen by Factor XIIIa. However, interaction of vWF with collagen-coated surfaces occurs only when the surface is coated with native collagen. Replacement with heat-denatured collagen or other macromolecules present in plasma, like albumin or gamma globulin, completely abolishes vWF binding. This pattern of binding is distinct from that observed with fibronectin, which also has a collagen-binding domain. In contrast to vWF, fibronectin has a higher affinity for denatured forms of collagen and, for example, binds more avidly to gelatin than to native collagen (35).

Although we have clearly shown a high affinity interaction of vWF with purified monomeric types I and III collagen, studies to define the nature of binding in the complex milieu of the vessel wall or in the matrix produced by cultured cells suggest that vWF may interact with additional matrix component. For example, Wagner et al. (13) have recently reported that inhibition of collagen biosynthesis by cultured endothelial cells did not eliminate the presence of vWF from the secreted matrix. However, one serious limitation of these studies is the difficulty of assessing the extent of inhibition of collagen synthesis, since matrix-associated collagen was not quantified. In addition, the amount of vWF in matrix was determined by indirect immunofluorescence which is, at best, a semiquantitative technique. In support of our findings, Sixma and colleagues (36) have reported that a monoclonal antibody can be produced which prevents vWF binding to vascular subendothelium. This same antibody also prevents vWF binding to surfaces coated with microfibrillar collagen (36). These data support our observation that vWF interacts with collagen. We have not yet compared the binding capacities of purified collagen subtypes in our assay, nor have we varied the physical form of the collagen. Nevertheless, it is tempting to speculate that the binding and covalent cross-linking of vWF to collagen may facilitate vWF-mediated platelet adhesion by increasing the effective concentration of vWF at sites of vascular injury.

\section{Acknowledgments}

This research was supported by National Institutes of Health grants 2 T32 HL07523, 5 F32 HL06683, HL34787, HL33014, HL29512, and the W. C. Moloney Fund for Clinical Hematology.

\section{References}

1. Meyer, D., and H. R. Baumgartner. 1983. Role of von Willebrand factor in platelet adhesion to the subendothelium. Br. J. Haem. 54:1-9.

2. Tschopp, T. B., J. H. Weiss, and H. R. Baumgartner. 1974. Decreased adhesion of platelets to subendothelium in von Willebrand's disease. J. Lab. Clin. Med. 83:296-300.

3. Sakariassen, K. S., P. A. Bolhuis, and J. J. Sixma. 1979. Human blood platelet adhesion to artery subendothelium is mediated by factor VIII-von Willebrand factor bound to the subendothelium. Nature (Lond.). 279:636-638.

4. Baumgartner, H. R., T. B. Tschopp, and D. Meyer. 1980. Shear rate-dependent inhibition of platelet adhesion and aggregation on col- 
lagenous surfaces by antibodies to human factor VIII/von Willebrand factor. Br. J. Haem. 44:127-139.

5. Booyse, F. M., A. J. Quarfoot, and S. Feder. 1982. Culture-produced subendothelium. I. Platelet interaction and properties. Haemostasis. 11: 49-61.

6. Booyse, F. M., S. Feder, and A. J. Quarfoot. 1982. Culture-produced subendothelium. II. Effect of plasma, FVIIIR:WF and fibronectin on interaction of normal platelets and in normal and von Willebrand porcine aortic subendothelium. Thromb. Res. 28:299-311.

7. Santoro, S. A., and J. F. Cowan. 1982. Adsorption of von Willebrand factor by fibrillar collagen-implications concerning the adhesion of platelets to collagen. Collagen Rel. Res. 2:31-43.

8. Nyman, D. 1980. Von Willebrand factor-dependent platelet aggregation and adsorption of factor VIII related antigen by collagen. Thromb. Res. 17:209-214.

9. Santoro, S. A. 1981. Adsorption of von Willebrand Factor/Factor VIII by the genetically distinct interstitial collagens. Thromb. Res. 21: 689-693.

10. Morton, L. F., B. Griffin, D. S. Pepper, and M. J. Barnes. 1983. The interaction between collagens and factor VIII/von Willebrand factor: investigation of the structural requirements for interaction. Thromb. Res. 32:545-556.

11. Santoro, S. A., and L. W. Cunningham. 1980. Collagen-mediated platelet aggregation: the role of multiple interactions between the platelet surface and collagen. Thromb. Haemost. 43:158-162.

12. Legrand, Y. J., F. Fauvel, M. M. Gutman, J. P. Muk, G. Tobelem, H. Souchon, A. Karniguian, and J. P. Caen. 1980. Microfibrils (MF) platelet interaction: requirement of von Willebrand factor. Thromb. Res. 19:737-739.

13. Wagner, D., M. Urban-Pickering, and V. Marder. 1984. Von Willebrand protein binds to extracellular matrices independently of collagen. Proc. Natl. Acad. Sci. USA. 81:471-475.

14. Johansson, S., and M. Hook. 1980. Heparin enhances the rate of binding of fibronectin to collagen. Biochem. J. 187:521-524.

15. Del Rosso, M., R. Cappelletti, M. Viti, S. Vannuchi, and V. Chiarugi. 1981. Binding of the basement membrane glycoprotein laminin to glycosaminoglycans. Biochem. J. 199:699-704.

16. Robinson, R., I. Likar, and L. Likar. 1975. Glycosaminoglycans and arterial disease. Chapter IV. In Monographs on Atherosclerosis. Vol. 5. J. Kirk, D. Kritchevsky, O. J. Pollak, and H. Sims, editors. S. Karger, New York. 34-55.

17. Laterra, J., and L. Culp. 1982. Differences in hyaluronate binding to plasma and cell surface fibronectins-requirement for aggregation. $J$. Biol. Chem. 257:719-726.

18. Folk, J. E., and J. S. Finlayson. 1977. The $\epsilon(\gamma$-glutamyl) lysine cross-link and the catalytic role of transglutaminases. Adv. Protein Chem. 31:1-133.

19. Mosher, D., P. Schad, and H. Kleinman. 1979. Cross-linking of fibronectin to collagen by blood coagulation factor XIIIa. J. Clin. Invest. 64:781-787.

20. Sakata, Y., and N. Aoki. 1980. Cross-linking of $\alpha_{2}$-plasmin inhibitor to fibrin by fibrin stabilizing factor. J. Clin. Invest. 65:290-297.
21. Furie, M., and D. Rifkin. 1980. Proteolytically derived fragments of human plasma fibronectin and their localization within the intact molecule. J. Biol. Chem. 255:3134-3140.

22. Mosher, D., P. Schad, and J. Vann. 1980. Cross-linking of collagen and fibronectin by factor XIIIa. Localization of participating glutaminyl residues to a tryptic fragment of fibronectin. J. Biol. Chem. 255:11811188.

23. Erickson, H. P., N. A. Carrell, and J. McDonagh. 1981. The structure of fibronectin. J. Cell. Biol. 91:673-678.

24. Skrzynia, C., H. M. Reisner, and J. McDonagh. 1982. Characterization of the catalytic subunit of factor XIII by radioimmunoassay. Blood. 60:1089-1095.

25. Kao, K. J., S. V. Pizzo, and P. A. McKee. 1979. Demonstration and characterization of specific binding sites for factor VIII/von Willebrand factor on human platelets. J. Clin. Invest. 63:656-664.

26. Lowry, O. H., N. J. Rosebrough, A. L. Farr, and R. Randall. 1951. Protein measurement with the folin phenol reagent. J. Biol. Chem. 193:265-275.

27. Laemmli, U. K. 1970. Cleavage of structural proteins during the assembly of the head of bacteriophage T4. Nature (Lond.). 227:680-685.

28. Shaw, E., and C. Kettner. 1979. D-Phe-Pro-ArgCH ${ }_{2} \mathrm{Cl}-\mathrm{A}$ selective affinity label for thrombin. Thromb. Res. 14:969-972.

29. Allain, J. P., J. A. Cooper, R. H. Wagner, and K. M. Brinkhous. 1975. Platelets fixed with paraformaldehyde: a new reagent for assay of von Willebrand factor and platelet-aggregating factor. J. Lab. Clin. Med. 85:318-328.

30. Howard, M. A., and B. G. Firkin. 1971. Ristocetin-a new tool in the investigation of platelet aggregation. Thromb. Diath. Haemorrh. 26:362-369.

31. Olson, J. D., W. J. Brockway, D. N. Fass, M. A. Magnusson, and E. J. W. Bowie. 1975. Evaluation of ristocetin-Willebrand factor assay and ristocetin-induced platelet aggregation. Am. J. Clin. Path. 63: 210-218.

32. Csako, G., E. Suba, and A. Herp. 1981. Similarities and dissimilarities between the binding ability of Clq and collagen. Clin. Exp. Immunol. 44:181-190.

33. Scott, D. M., B. Griffin, D. S. Pepper, and M. J. Barnes. 1981. The binding of purified factor VIII/von Willebrand factor to collagens of differing type and form. Thromb. Res. 24:467-472.

34. Houdijk, W. P. M., K. S. Sakariassen, P. F. E. M. Nievelstein, and J. J Sixma. 1985. Role of factor VIII-von Willebrand factor and fibronectin in the interaction of platelets in flowing blood with monomeric and fibrillar human collagen types I and III. J. Clin. Invest. 75:531-540.

35. Mosher, D. 1980. Fibronectin. Prog. Hemost. Thromb. 5:111151.

36. Sixma, J., K. Sakariassen, H. V. Stel, W. P. Houdijk, D. W. In der Maur, R. Hamer, P. G. de Groot, and J. van Mourik. 1984. Functional domains on von Willebrand factor. Recognition of discrete tryptic fragments by monoclonal antibodies that inhibit interaction of von Willebrand factor with platelets and with collagen. J. Clin. Invest. 74:736744. 